\title{
Deconvolution of Soft lonization Mass Spectra of Chlorinated Paraffins To Resolve Congener Groups
}

\author{
Bo Yuan,,$^{* \dagger}{ }^{\dagger}$ Tomas Alsberg, ${ }^{\dagger}$ Christian Bogdal, ${ }^{\ddagger}, \S$ Matthew MacLeod, ${ }^{\dagger}$ Urs Berger, ${ }^{\|}$Wei Gao, ${ }^{\perp}$
} Yawei Wang, ${ }^{\perp}$ and Cynthia A. de Wit ${ }^{\dagger}$

\begin{abstract}
${ }^{\dagger}$ Department of Environmental Science and Analytical Chemistry, Stockholm University, Svante Arrhenius väg 8, SE-10691 Stockholm, Sweden

${ }^{\ddagger}$ Institute for Chemical and Bioengineering, Swiss Federal Institute of Technology, ETH Zürich, Vladimir-Prelog-Weg 1, CH-8093 Zürich, Switzerland

${ }^{\S}$ Institute for Sustainability Sciences, Agroscope, Reckenholzstrasse 191, CH-8046 Zürich, Switzerland

"Department Analytical Chemistry, Helmholtz Centre for Environmental Research-UFZ, Permoserstraße 15, DE-04318 Leipzig, Germany

${ }^{\perp}$ State Key Laboratory of Environmental Chemistry and Ecotoxicology, Research Center for Eco-Environmental Sciences, Chinese Academy of Sciences, Shuangqing Road 18, CN-100085 Beijing, China
\end{abstract}

\section{Supporting Information}

ABSTRACT: We describe and illustrate a three-step dataprocessing approach that enables individual congener groups of chlorinated paraffins (CPs) to be resolved in mass spectra obtained from either of two soft ionization methods: electron capture negative ionization mass spectrometry (ECNI-MS) or atmospheric pressure chemical ionization mass spectrometry (APCI-MS). In the first step, general fragmentation pathways of $\mathrm{CPs}$ are deduced from analysis of mass spectra of individual CP congeners. In the second step, all possible fragment ions in the general fragmentation pathways of CPs with 10 to 20 carbon atoms are enumerated and compared to mass spectra of $\mathrm{CP}$ mixture standards, and a deconvolution algorithm is applied to identify fragment ions that are actually observed. In the third step, isotope permutations of the observed fragment ions are calculated and used to identify isobaric overlaps, so that mass intensities of individual CP congener groups can be deconvolved from the unresolved isobaric ion signal intensities in mass spectra. For a specific instrument, the three steps only need to be done once to enable deconvolution of CPs in unknown samples. This approach enables congener group-level resolution of CP mixtures in environmental samples, and it opens up the possibility for quantification of congener groups.

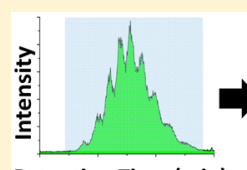

Retention Time (min) $16 \% \quad 6 \%$

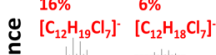
空 $34 \% \quad 15 \%$ (C) $\left[\mathrm{C}_{12} \mathrm{H}_{17} \mathrm{Cl}_{7}\right] \cdot\left[\mathrm{C}_{12} \mathrm{H}_{16} \mathrm{Cl}_{7}\right]$ $\supseteq \frac{11.1}{16 \%}$ T⿱一兀) $13 \%$ $\frac{\pi}{20}\left[\mathrm{C}_{12} \mathrm{H}_{15} \mathrm{Cl}_{7}\right]^{-} \cdot\left[\mathrm{C}_{12} \mathrm{H}_{13} \mathrm{Cl}_{7}\right.$

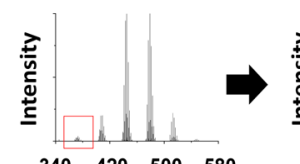

$340 \quad \begin{array}{lll}420 & 500 & 580 \\ \mathrm{~m} / \mathrm{z} & \end{array}$

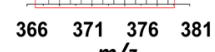
$\mathrm{m} / \mathrm{z}$

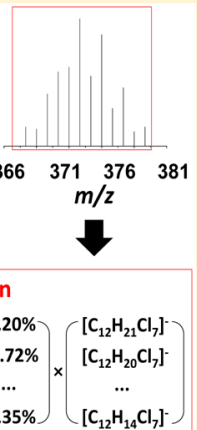

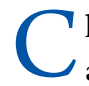
hlorinated paraffins (CPs) are mixtures of chlorinated $n$ alkanes. They are widely used product additives, with numerous applications that include use as flame retardants and plasticizers in plastics, paints, sealants, and adhesives, as coolants and lubricants in metal-cutting, and as fatliquors in leather processing. ${ }^{1}$ Global production of CPs has increased to more than 1 million $\mathrm{t} / \mathrm{a}$ in $2009 .^{2} \mathrm{CP}$ mixtures can be divided into short-chain (SCCPs, $\mathrm{C}_{10}-\mathrm{C}_{13}$ ), medium-chain (MCCPs, $\mathrm{C}_{14}-\mathrm{C}_{17}$ ), and long-chain CPs (LCCPs, $\mathrm{C}_{\geq 18}$ ). The Persistent Organic Pollutants (POPs) Review Committee of the UN Stockholm Convention has listed SCCPs as a POP candidate, citing evidence that SCCPs occur in remote areas such as the Arctic, are toxic to aquatic organisms and are potentially carcinogenic. ${ }^{3}$ However, scientific studies on the occurrence and behavior of CPs in humans and the environment are still rare. The major reason for this paucity of data is the challenge posed by $\mathrm{CP}$ analysis, even using modern separation and detection techniques.

Technical CP mixtures contain thousands of congeners with the general elemental composition $\mathrm{C}_{n} \mathrm{H}_{2 n+2-m} \mathrm{Cl}_{m}$ (hereafter abbreviated as $\mathrm{C}_{n} \mathrm{Cl}_{m}$ ). Complete separation of individual CPs has so far not been achieved, ${ }^{4}$ although two-dimensional gaschromatography $(\mathrm{GC} \times \mathrm{GC})$ techniques show considerable promise. ${ }^{5}$ The identification of CP congener groups (i.e., CPs with a given number of carbon and chlorine atoms) relies on detection of pseudomolecular ions by soft ionization mass spectrometry. ${ }^{6}$ The large number of isomers, chlorine isotope patterns, and multiple fragmentations of different $\mathrm{CP}$ congeners all contribute to an extremely complex mass spectrum and

Received: March 24, 2016

Accepted: August 17, 2016

Published: August 17, 2016 
result in mass interference for pseudomolecular as well as possible confirmation ions, both within and between congener groups. High instrument resolving power is required to separate interfering ions of the same nominal mass (i.e., isobaric mass). ${ }^{7}$ For instance, to separate $\left[\mathrm{C}_{10} \mathrm{Cl}_{8}-\mathrm{Cl}\right]^{-}\left({ }^{12} \mathrm{C}_{10}{ }^{1} \mathrm{H}_{14}{ }^{35} \mathrm{Cl}_{6}{ }^{37} \mathrm{Cl}\right.$. , $m / z 380.8886 \mathrm{amu})$ from $\left[\mathrm{C}_{10} \mathrm{Cl}_{6}+\mathrm{Cl}\right]^{-}\left({ }^{12} \mathrm{C}_{10}{ }^{1} \mathrm{H}_{16}{ }^{35} \mathrm{Cl}_{7 .}^{-}\right.$, $\mathrm{m} / z 380.9072 \mathrm{amu})$, a resolving power of at least $20500(10 \%$ valley definition) is required. The required resolving powers are significantly higher than those of commonly used magnetic sector or time-of-flight (TOF) high-resolution instruments in routine resolution mode (typically 10000 ). In addition, certain fragment ion species, such as the three species $\left[\mathrm{C}_{10} \mathrm{Cl}_{8}-\mathrm{Cl}\right]^{-}$, $\left[\mathrm{C}_{10} \mathrm{Cl}_{7}-\mathrm{H}\right]^{-}$and $\left[\mathrm{C}_{10} \mathrm{Cl}_{9}-2 \mathrm{Cl}+\mathrm{H}\right]^{-}$, possess identical chemical sum formulas (in this case, $\mathrm{C}_{10} \mathrm{H}_{14} \mathrm{Cl}_{7}$ ) and therefore cannot be resolved by mass spectrometry, even with infinite resolving power.

Mathematical deconvolution techniques have been applied to resolve signals of high-mass molecules in the field of protein mass spectrometry and to overcome the limitations of instruments with poor resolution. ${ }^{8-12}$ Deconvolution can allow unique identification of individual ion signals within a cluster of overlapping masses. ${ }^{13,14}$ Some deconvolution methods determine the relative amounts of an individual ion by reconstructing the unresolved mass spectra from the isolated isotopic patterns of the ion candidates. ${ }^{15}$ However, these applications depend on knowledge of possible ion candidates, and complete knowledge of overlapping ions of CPs is not available due to their compositional complexity and the lack of information about the content of commercial CP products.

Recently, Bogdal and co-workers introduced a method for analysis of CP mixtures in environmental samples based on the identification of chloride adducts by deconvolution of chlorineenhanced atmospheric pressure chemical ionization (APCI) mass spectra. ${ }^{7}$ However, possible mass interferences due to overlapping fragment ions were not discussed. The present study is a logical extension of the method presented by Bogdal et al. Here, we describe a data-processing approach to identify individual $\mathrm{C}_{n} \mathrm{Cl}_{m}$ isobaric mass signals in two commonly applied soft ionization mass spectrometry methods, electron capture negative ionization mass spectrometry (ECNI-MS) and APCI-MS. For either ionization method, all possible fragment ions of $\mathrm{C}_{10}-\mathrm{C}_{20} \mathrm{CPs}$ can be deduced progressively by mass spectral analysis of CP chemical standards. Isotopic distributions of all the possible ions are enumerated to identify isobaric overlaps. Thereafter, $\mathrm{C}_{n} \mathrm{Cl}_{m}$ (i.e., specific congener groups) can be identified from the isobaric ion signals unresolved by the instrument. Typical applications are described, and requirements to extend the method to quantify concentrations of congener groups are identified.

\section{CHEMICALS AND INSTRUMENTS}

CP Standards. We purchased eight individual CP congeners with defined molecular structure, including carbon chain lengths $10,11,12$, and 14 , with 4 to 8 chlorine atoms. We also purchased three $\mathrm{CP}$ chain length standards with a defined carbon chain length $\left(\mathrm{C}_{12}\right)$ but varying $\mathrm{Cl}$ substitution. Finally, seven $\mathrm{CP}$ mixture standards with variable chain length and chlorination degree between $42 \%$ and $63 \%$ were selected for this study. For a detailed list of standards, see the Supporting Information.

Instruments. Three different GC/ECNI-MS and one LC/ APCI-MS were used in this study: (1) GC/ECNI-quadrupole time-of-flight (QTOF) HRMS (Agilent 7200, Santa Clara,
USA); (2) GC/ECNI-magnetic sector HRMS (MS: Thermo Finnigan MAT95, Bremen, Germany); (3) GC/ECNI-quadrupole LRMS (Thermo DSQ II, Bremen, Germany); (4) APCIQTOF (Waters QTOF Premier, Manchester, U.K.). For detailed instrumental methods, see the Supporting Information. The GC was only used to separate solvents from the $\mathrm{CP}$ analytes, before introducing the CPs into the ECNI-ion source. For the APCI system, the autoinjector of the LC system was used for direct injection into the ion source without chromatography.

Data Acquisition. Mass spectra of the CPs using ECNIQTOF MS and APCI-QTOF MS (full-scan acquisition, centroid mode, background subtracted) were obtained by the MassHunter B.06.00 and the MassLynx V4.1 data system, respectively. The magnetic sector HRMS was operated in selected ion monitoring (SIM) mode using the Xcalibur V2.2 data system. The flow injection peak of an individual $\mathrm{m} / \mathrm{z}$ in APCI-MS was integrated by an automatic algorithm to avoid inconsistencies of manual integration. For integration of "humps" resulting from the gas chromatographic introduction, see the Supporting Information, Figure S-1. In QTOF MS data acquisition, signals were recorded as centroid $\mathrm{m} / z$ including all ions that were unresolved within a given mass range. The mass range can be calculated from the resolving power; for example, an observed centroid $m / z 444.8706$ amu using a QTOF instrument with a resolving power of 10000 represents the ions within $m / z\{444.8706-444.8706 / 10000,444.8706+$ $444.8706 / 10000\}=\{444.8261,444.9151\} \mathrm{amu}$.

\section{DATA-PROCESSING APPROACH}

We processed the data acquired for the three types of $\mathrm{CP}$ standards (individual CP congeners, CP chain length standards, CP mixture standards) in three sequential steps with repeated application of deconvolution to find isobaric overlaps that occur at each centroid $\mathrm{m} / z$. The approach is summarized in the flowchart in Figure 1. For a specific instrument, these three steps only need to be done once, then the output of step 3 can be applied for resolving $\mathrm{C}_{n} \mathrm{Cl}_{m}$ in unknown samples. The principles of the deconvolution and the data-processing steps are described below.

Principle of Deconvolution. We apply mathematical deconvolution to resolve individual abundances of overlapping ions. Its principle has been described elsewhere ${ }^{15,16}$ and is briefly presented here. The intensity of the $\mathrm{m} / z$ observed in mass spectra is equal to the sum of the intensities of the individual overlapping ions at the same centroid $\mathrm{m} / z$, which in matrix notation is

$$
\left(\begin{array}{c}
I_{1} \\
I_{2} \\
\ldots \\
I_{i}
\end{array}\right)=\left(\begin{array}{cccc}
A_{11} & A_{12} & \ldots & A_{1 j} \\
A_{21} & A_{22} & \ldots & A_{2 j} \\
\ldots & \ldots & \ldots & \ldots \\
A_{i 1} & A_{i 2} & \ldots & A_{i j}
\end{array}\right) \cdot\left(\begin{array}{c}
X_{1} \\
X_{2} \\
\ldots \\
X_{j}
\end{array}\right) \rightarrow\{I\}=\{A\} \cdot\{X\}
$$

where $\{I\}$ is a vector containing the intensities of measured $\mathrm{m} / z$ in the unresolved spectra (input), $i$ is the number of measured $m / z$, and $j$ is the number of possible ions $(i \geq j) .\{A\}$ is an $i \times j$ matrix containing the isotope pattern abundances of all ions (calculated). Solution by least-squares optimization generates the relative amounts of individual ions in overlapping mass spectra in the vector $\{X\}$ (output, unknown of the equation 


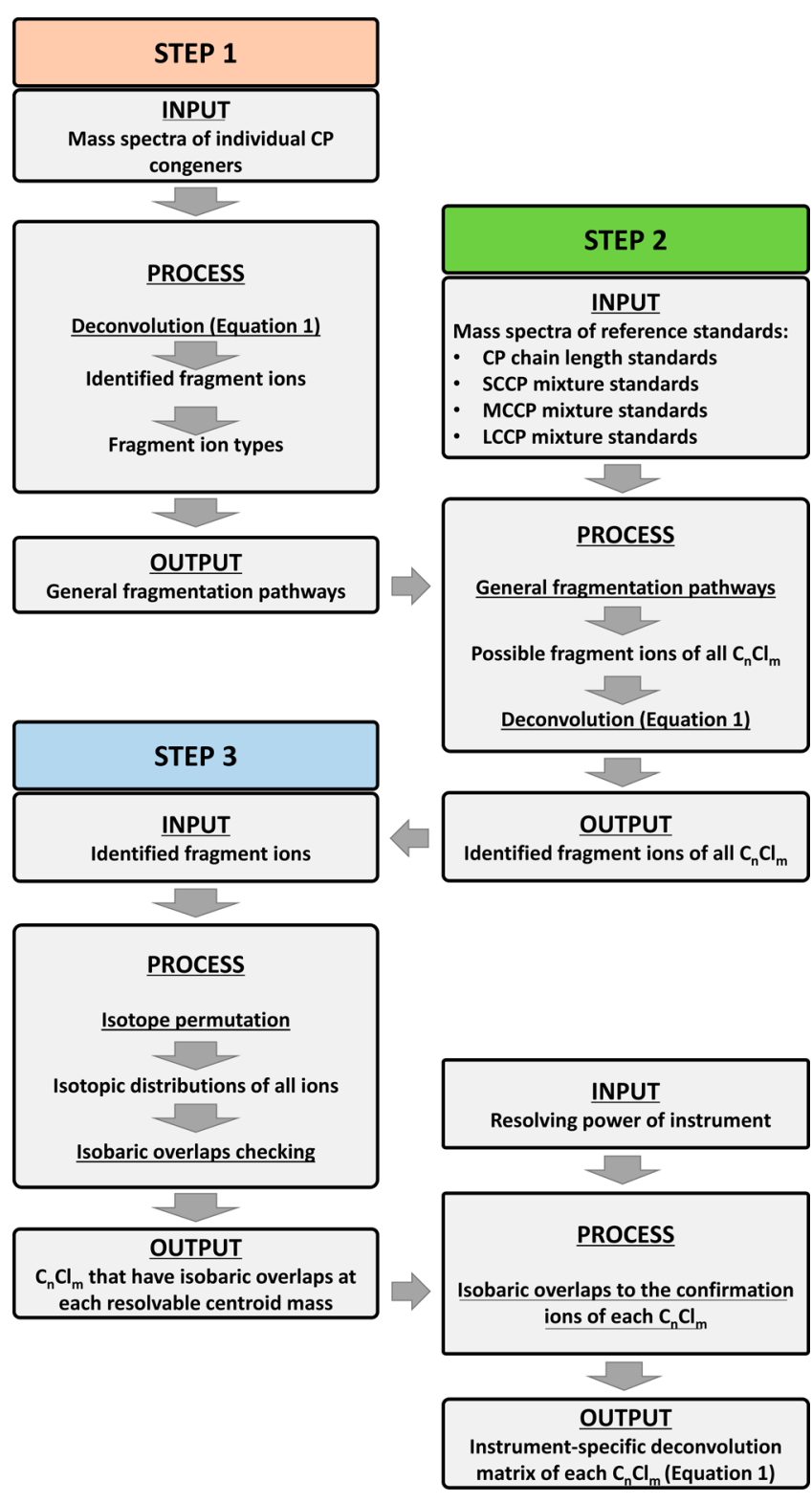

Figure 1. Flowchart summary of the data-processing steps.

system). For the isotopic calculation (matrix A) and the leastsquares algorithm, see the Supporting Information.

Quality control of the deconvolution consists of mass spectrum reconstruction and centroid mass shift analysis. The former calculates the percent difference value (DV) between the reconstructed and the measured mass spectra in order to evaluate the performance of deconvolution. The equation used to determine $\mathrm{DV}$ is ${ }^{16}$

$$
\begin{aligned}
\mathrm{DV} & =100 \cdot\left|\frac{\text { reconstructed }- \text { measured }}{\frac{\text { reconstructed }+ \text { measured }}{2}}\right| \\
& =100 \cdot\left|\frac{\sum \sum X_{j} \cdot A_{i j}-\sum I_{i}}{\frac{\sum \sum X_{j} \cdot A_{i j}+\sum I_{i}}{2}}\right|
\end{aligned}
$$

Centroid mass shift analysis compares the observed centroid mass and the calculated one (based on the knowledge of instrumental mass resolution) to verify the deconvolution result
$\{X\}$. The calculated centroid mass is approximated from the weighted average of the overlapping $\mathrm{m} / \mathrm{z}^{15}$

$$
m / z=\frac{\sum\left(X_{j} \cdot m / z_{j}\right)}{\sum X_{j}}
$$

where $m / z_{j}$ is the exact mass-to-charge ratio of the fragment ion $j$.

Data-Processing Steps. Step 1: Deduction of General Fragmentation Pathways. The general fragmentation pathway for a molecule specifies the fragment ions that could be observed using mass spectrometry. The first step in our approach is to deduce general fragmentation pathways of CPs from ions identified in soft ionization mass spectra of individual $\mathrm{CP}$ congeners. Deconvolution was performed in each mass cluster, and ion candidates of deconvolution were selected on the basis of previous studies. ${ }^{17-21}$ Furthermore, APCI-QTOFMSMS spectra of the SCCP $63.0 \% \mathrm{Cl}$ mixture standard were deconvolved to provide a full picture of $\mathrm{CP}$ fragmentation in APCI-MS. General fragmentation pathways were deduced from common characteristics of the fragmentations of different CPs. Our general fragmentation pathways are assumed to be applicable to all $\mathrm{C}_{n} \mathrm{Cl}_{m}$ and to include all possible fragment ions. However, whether the predicted fragment ions are formed or not varies among different $\mathrm{C}_{n} \mathrm{Cl}_{m}$, and hence, the ions predicted by the general pathway need to be screened against observed mass spectra of well-characterized CP standards in step 2.

Step 2: Fragment Ion Screening. The fragment ions proposed in step 1 were screened by deconvolving mass spectra of CP mixture standards in both ECNI-MS and APCIMS. Fragment ions of $\mathrm{C}_{10-13}$ homologues were screened using $\mathrm{C}_{12}$ chain length standards as well as SCCP $51.5 \% \mathrm{Cl}, 55.5 \% \mathrm{Cl}$, and $63.0 \% \mathrm{Cl}$ standards. Fragment ions of $\mathrm{C}_{14-17}$ were screened using $\mathrm{MCCP} \quad 42.0 \% \mathrm{Cl}, 52.0 \% \mathrm{Cl}$, and $57.0 \% \mathrm{Cl}$ standards. Fragment ions of $\mathrm{C}_{18-20}$ were screened using the LCCP $49.0 \% \mathrm{Cl}$ standard. In the mass spectrum of each standard, a $\mathrm{C}_{n} \mathrm{Cl}_{m}$ congener group was first identified by its confirmation ion, which was $[\mathrm{M}-\mathrm{Cl}]^{-}$in ECNI-MS and $[\mathrm{M}+\mathrm{Cl}]^{-}$in APCI-MS. All possible fragment ions of identified $\mathrm{C}_{n} \mathrm{Cl}_{m}$ were then enumerated according to the general fragmentation pathways that were derived in step 1 . Isotopic distributions of each fragment ion were calculated for deconvolution from theoretical abundances of chlorine, carbon, and hydrogen isotopes. Mass spectra were divided into mass clusters of $\mathrm{C}_{n} \mathrm{Cl}_{m}$ according to centroid $\mathrm{m} / z$ of the confirmation ions, and deconvolution was performed for each cluster. On the basis of the $m / z$ values of each cluster, possible overlapping ions were deconvolved into their relative amounts. Fragment ions with a positive contribution in the deconvolution of the mass spectrum of any of the investigated standards were confirmed to be present and considered in step 3 .

Step 3: Investigation of Isobaric Interferences. In each soft ionization method, the $\mathrm{m} / z$ value and the theoretical abundance of the isotopic distributions of all confirmed fragment ions from step 2 were exhaustively enumerated to check for isobaric overlaps. The aim was to sort out isobaric interferences for the confirmation ion of each $\mathrm{C}_{n} \mathrm{Cl}_{m}$ at the instrumental mass resolution. $\Delta m / z$ between the confirmation ion and the interference indicated the required resolving power of the mass spectrometer to distinguish them from each other. Therefore, the deconvolution matrix of $\mathrm{C}_{n} \mathrm{Cl}_{m}$ was constructed according to the resolving power of each specific instrument 
Table 1. Identified Congener-Specific Ions in the ECNI Mass Spectra of CP Congeners (Source Temperature: $\left.150{ }^{\circ} \mathrm{C}\right)^{a, b}$

\begin{tabular}{|c|c|c|c|c|c|c|c|c|}
\hline ion candidates & $\begin{array}{c}1,2,5,6,9,10- \\
\mathrm{C}_{10} \mathrm{H}_{16} \mathrm{Cl}_{6}\end{array}$ & $\begin{array}{c}1,5,5,6,6,10- \\
\mathrm{C}_{10} \mathrm{H}_{16} \mathrm{Cl}_{6}\end{array}$ & $\begin{array}{c}1,2,4,5,6,9,10- \\
\mathrm{C}_{10} \mathrm{H}_{15} \mathrm{Cl}_{7}\end{array}$ & $\begin{array}{c}1,1,1,3,10,11- \\
\mathrm{C}_{11} \mathrm{H}_{18} \mathrm{Cl}_{6}\end{array}$ & $\begin{array}{c}1,1,1,3,9,11,11,11- \\
\mathrm{C}_{11} \mathrm{H}_{16} \mathrm{Cl}_{8}\end{array}$ & $\begin{array}{c}1,1,1,3,11,12- \\
\mathrm{C}_{12} \mathrm{H}_{20} \mathrm{Cl}_{6}\end{array}$ & $\begin{array}{c}1,1,1,3,10,12,12,12- \\
\mathrm{C}_{12} \mathrm{H}_{18} \mathrm{Cl}_{8}\end{array}$ & $\begin{array}{l}1,2,13,14- \\
\mathrm{C}_{14} \mathrm{H}_{26} \mathrm{Cl}_{4}\end{array}$ \\
\hline$[\mathrm{M}+\mathrm{Cl}-2 \mathrm{H}]^{-}$ & & & & & & & & \\
\hline$[\mathrm{M}+\mathrm{Cl}-\mathrm{H}]^{-}$ & & & & & & & & \\
\hline$[\mathrm{M}+\mathrm{Cl}]^{-}$ & & & & & & ) & & \\
\hline$[\mathrm{M}-2 \mathrm{H}]^{-}$ & & & & & & & & \\
\hline$[\mathrm{M}-\mathrm{H}]^{-}$ & & & & & & & & \\
\hline$[\mathrm{M}]^{-}$ & & & & & & & & \\
\hline$[\mathrm{M}+\mathrm{H}]^{-}$ & & & & & & & & \\
\hline$[\mathrm{M}-\mathrm{HCl}-\mathrm{H}]^{-}$ & & & & & & & & \\
\hline$[\mathrm{M}-\mathrm{HCl}]^{-}$ & & & & & & & & \\
\hline$[\mathrm{M}-\mathrm{Cl}]^{-}$ & & & & & & & & \\
\hline$[\mathrm{M}-\mathrm{Cl}+\mathrm{H}]^{-}$ & & & & & & & & \\
\hline$[\mathrm{M}-2 \mathrm{HCl}]^{-}$ & & & & & & & & \\
\hline$[\mathrm{M}-\mathrm{HCl}-\mathrm{Cl}]^{-}$ & & & & & & & & \\
\hline$[\mathrm{M}-2 \mathrm{Cl}]^{-}$ & & & & & & & & \\
\hline$[\mathrm{M}-2 \mathrm{Cl}+\mathrm{H}]^{-}$ & & & & & & & & \\
\hline$[\mathrm{M}-2 \mathrm{Cl}-\mathrm{HCl}]^{-}$ & & & & & & & & \\
\hline$[\mathrm{M}-3 \mathrm{Cl}]^{-}$ & & & & & & & & \\
\hline$[\mathrm{M}-3 \mathrm{Cl}+\mathrm{H}]^{-}$ & & & & & & & & \\
\hline
\end{tabular}

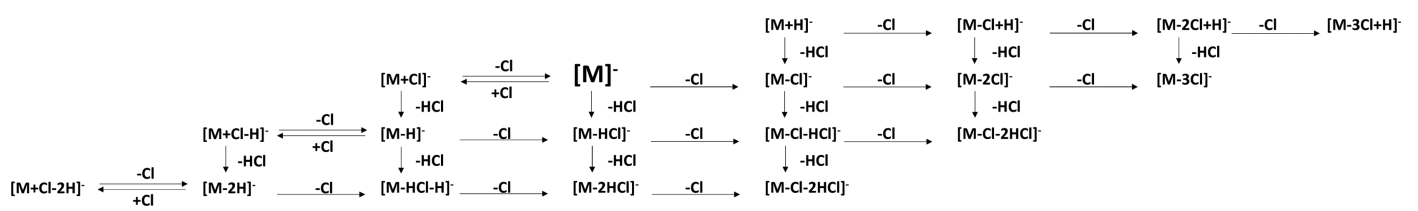

Figure 2. General fragmentation pathways suggested for CPs in ECNI-MS.

because different nonresolved interferences needed to be considered.

\section{RESULTS AND DISCUSSION}

Data-Processing Approach in ECNI. Step 1: General Fragmentation Pathways. The identified fragment ions of eight individual $\mathrm{CP}$ congeners are shown in Table 1 . The ions are $[\mathrm{M} \pm \mathrm{Cl}]^{-},[\mathrm{M} \pm x \mathrm{H}]^{-},[\mathrm{M}-\mathrm{HCl}]^{-},[\mathrm{M}-2 \mathrm{Cl}]^{-}$, and so on. The ion $[\mathrm{M}-\mathrm{H}]^{-}$was reported by Gjos and Gustavsen. ${ }^{22}$ The ion may be formed via chloride adduction and loss of $\mathrm{HCl}$. An ion species of nominal formula with $[\mathrm{M}+\mathrm{H}]^{-}$is observed in three of the congeners. The ion could potentially be formed via substitution of a chlorine with a hydrogen and addition of $\mathrm{Cl}^{-}$. CP congeners were analyzed by three ECNI-MS instruments, each with a specific reagent gas (i.e., argon, methane, and ammonia) and using an ion source temperature of $150{ }^{\circ} \mathrm{C}$ because Tomy et al. ${ }^{17}$ reported that low source temperatures favor formation of $[\mathrm{M}-\mathrm{Cl}]^{-}$. No unexpected ion species were observed. The observed fragment ions in Table 1 indicate that the fragmentation of CPs is generally limited to successive losses of $\mathrm{HCl}$ and/or $\mathrm{Cl}$. On the basis of these observations, our proposed general fragmentation pathways for CPs are shown schematically in Figure 2.

Our general fragmentation pathway analysis aimed to identify all possible fragment ions of CPs. Therefore, the general fragmentation pathways (Figure 2) include all ion species we observed in our ECNI-MS spectra of single CP congeners. The general fragmentation pathways shown in Figure 2 were used to enumerate possible fragment ions of congener groups $\mathrm{C}_{n} \mathrm{Cl}_{m}$ in general.
Six of our congener standards contained vicinal chlorines. Although 1,2-chlorine substitution patterns are less favored than 1,3-chlorine substitution, ${ }^{4} \mathrm{CP}$ congeners containing vicinal chlorines are considered to be representative of technical products. Vicinal chlorines should be especially common in CP congeners, in which the number of chlorines is more than half the number of carbons, such as $\mathrm{C}_{10} \mathrm{Cl}_{6}$ and $\mathrm{C}_{11} \mathrm{Cl}_{6}$.

Four of our congener standards contained trichloromethyl end groups $\left[-\mathrm{CCl}_{3}\right]$, e.g. $1,1,1,3,9,11,11,11$-octachloroundecane and 1,1,1,3,10,12,12,12-octachlorododecane. Some fragment ions such as $[\mathrm{M}+\mathrm{H}]^{-}$and $[\mathrm{M}-3 \mathrm{Cl}+\mathrm{H}]^{-}$may be generated because of this molecular structure, and it is notable that $[\mathrm{M}-\mathrm{Cl}]^{-}$is not observed in the MS spectra of these octachloro congeners. Trichloromethyl end groups are hardly observed in CP mixtures, ${ }^{23}$ so fragment ions of these congeners may not be as representative as fragment ions of the other congener standards.

The same maximum losses of $\mathrm{Cl} / \mathrm{HCl}$ are observed in $\mathrm{CP}$ congeners with the same number of chlorine substituents. As shown in Table 1, the fragment ions of the hexachloro congeners 1,2,5,6,9,10-hexachlorodecane, 1,5,5,6,6,10-hexachlorodecane, 1,1,1,3,10,11-hexachloroundecane, and 1,1,1,3,11,12-hexachlorododecane include $[\mathrm{M}+\mathrm{Cl}]^{-},[\mathrm{M} \pm$ $x \mathrm{H}]^{-}$and $[\mathrm{M}-\mathrm{Cl} \pm x \mathrm{H}]^{-}(x=0$ or 1$)$; both $1,1,1,3,9,11,11,11$-octachloroundecane and 1,1,1,3,10,12,12,12octachlorododecane generate $[\mathrm{M}-2 \mathrm{Cl}+x \mathrm{H}]^{-}$and $[\mathrm{M}-3 \mathrm{Cl}$ $\pm x \mathrm{H}]^{-}$. Therefore, we assume that the fragmentation pathways mainly depend on the number of chlorine substituents and their position, and they can be applied to CPs of different carbon chain lengths than the investigated ones.

Step 2: Fragment lon Screening. The screening of fragment ions for $\mathrm{C}_{12}$ chain length standards is illustrated in Figure 3. 


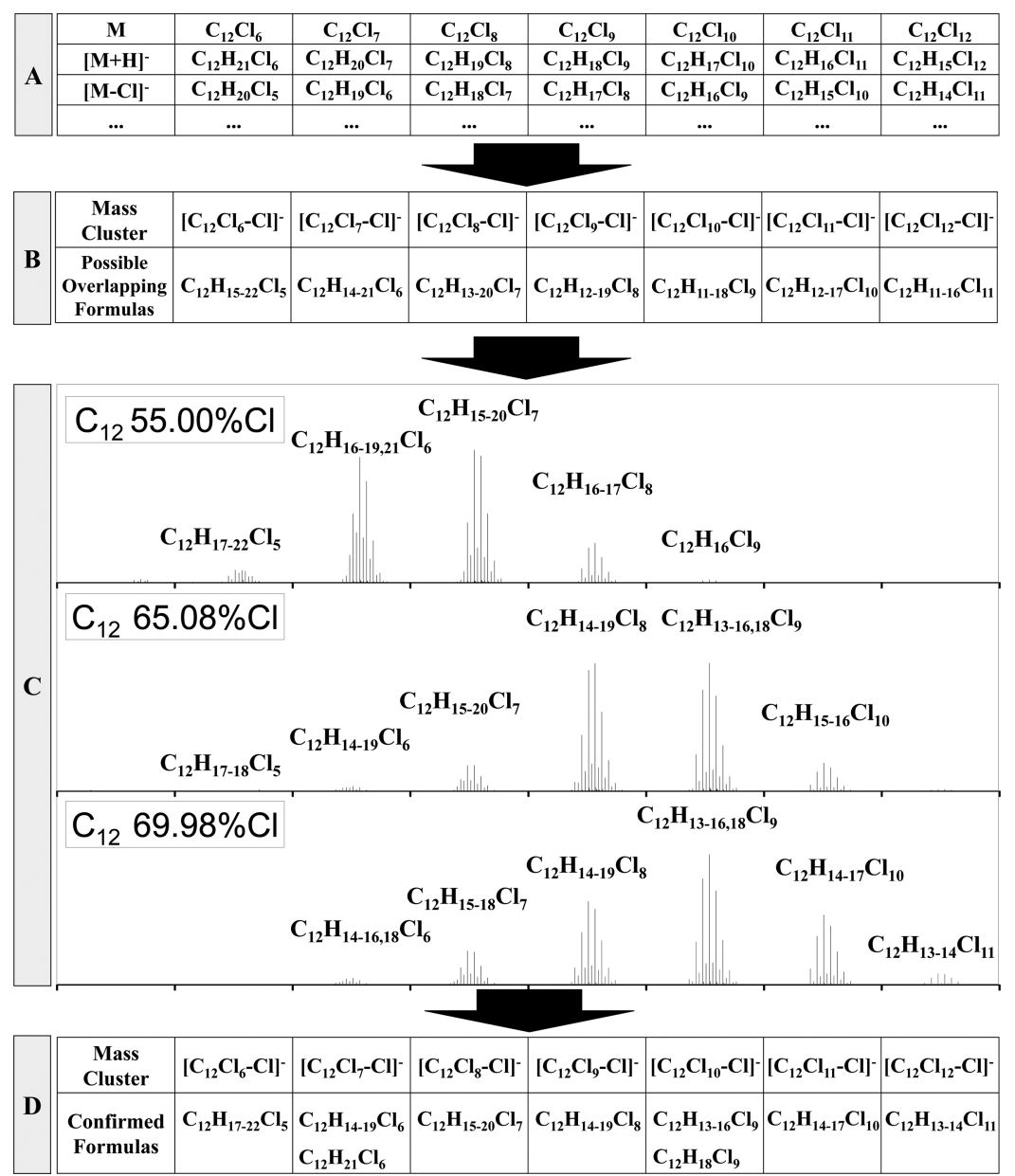

Figure 3. Illustration of the fragment ion screening procedure in ECNI-MS: (A) list the chemical formulas of all possible fragment ions based on the general fragmentation pathways (Figure 2); (B) sort possible overlapping formulas into $\left[\mathrm{C}_{n} \mathrm{Cl}_{m}-\mathrm{Cl}\right]^{-}$(confirmation ion) clusters; (C) deconvolve $\left[\mathrm{C}_{n} \mathrm{Cl}_{m}-\mathrm{Cl}\right]^{-}$clusters of $\mathrm{C}_{12}$ chain length standards to confirm the presence of formulas (eq 1); (D) sort confirmed formulas into $\left[\mathrm{C}_{n} \mathrm{Cl}_{m}-\mathrm{Cl}^{-}\right.$ clusters.

Chemical formulas of all possible fragment ions of individual $\mathrm{C}_{12} \mathrm{Cl}_{m}$ ( $m=4$ to 12$)$ were listed according to the general fragmentation pathways shown in Figure 2. Relative abundances of all chemical formulas were deconvolved from the mass spectra of $\mathrm{C}_{12}$ chain length standards (Table S-2). Following the same procedure, fragment ions of $\mathrm{C}_{10}$ to $\mathrm{C}_{16} \mathrm{CPs}$ were screened for within SCCP and MCCP mixture standards. Results are shown in Table 2. The responses of $\mathrm{C}_{17}$ to $\mathrm{C}_{20} \mathrm{CPs}$ were poor in the applied method, and therefore, no corresponding results are shown. For detailed deconvolution results of SCCP and MCCP mixture standards, see the Supporting Information (Table S-3 and S-4).

The mass clusters of $\left[\mathrm{C}_{n} \mathrm{Cl}_{m}-\mathrm{Cl}\right]^{-}$were reconstructed well by deconvolved chemical formulas, as illustrated with the $\mathrm{C}_{12} \mathrm{Cl}_{9}$ mass cluster in chain length standard $\mathrm{C}_{12} 69.98 \% \mathrm{Cl}$ in Figure 4. The mass cluster calculated from isotope abundances of $\left[\mathrm{C}_{12} \mathrm{Cl}_{9}-\mathrm{Cl}\right]^{-}$(which has a complete chemical formula of $\left.\left[\mathrm{C}_{12} \mathrm{H}_{17} \mathrm{Cl}_{8}\right]^{-}\right)$ranges from $\mathrm{m} / z 440.87$ to 448.87 . If the intensity of $\mathrm{m} / z$ 444.87, which has been used to quantify $\mathrm{C}_{12} \mathrm{Cl}_{9}$, ${ }^{17}$ only came from $\left[\mathrm{C}_{12} \mathrm{H}_{17} \mathrm{Cl}_{8}\right]^{-}$, the isotopic peak distribution would be different from the measured one (compare Figure $4 \mathrm{a}$ to $4 \mathrm{c}$ ). By deconvolution analysis, six chemical formulas that contribute to the mass cluster and their relative abundances were determined and superimposed as Figure $4 \mathrm{~b}$. The isotopic peak distribution reconstructed from the deconvolution has a percent difference (DV) of $0.09 \%$ compared to the measured distribution, whereas the DV of $\left[\mathrm{C}_{12} \mathrm{H}_{17} \mathrm{Cl}_{8}\right]^{-}$compared to the measured distribution is $42 \%$. The ion $\left[\mathrm{C}_{12} \mathrm{H}_{17} \mathrm{Cl}_{8}\right]^{-}$contributes only $55.9 \%$ of the intensity of $m / z 444.87$. This means that assuming $m / z 444.87$ was only due to $\left[\mathrm{C}_{12} \mathrm{H}_{17} \mathrm{Cl}_{8}\right]^{-}$would result in an overestimation of the true amount by almost a factor of 2 .

Centroid mass shift analysis of the above example further verified the deconvolution result. The most abundant isomer in the theoretical pattern of $\left[\mathrm{C}_{12} \mathrm{Cl}_{9}-\mathrm{Cl}\right]^{-}\left(\mathrm{C}_{12} \mathrm{H}_{17}{ }^{35} \mathrm{Cl}_{6}{ }^{37} \mathrm{Cl}_{2}\right)$ weighs $444.8780 \mathrm{amu}$, whereas the observed $\mathrm{m} / z$ was 444.8706 amu. The $m / z$ error is $17 \mathrm{ppm}$. When the exact $m / z$ values and deconvolved relative amounts of the six overlapping formulas are substituted into the centroid mass equation (eq 3), the calculated mass for the reconstruction was $444.8715 \mathrm{amu}$, the mass error of which was reduced to $2 \mathrm{ppm}$.

Step 3: Investigation of Isobaric Interferences. Isotopic patterns of the chemical formulas of all investigated $\mathrm{C}_{n} \mathrm{Cl}_{m}$ were exhaustively enumerated. Possible isobaric interferences with the confirmation ion $\left[\mathrm{C}_{n} \mathrm{H}_{2 n+2-m} \mathrm{Cl}_{m-1}\right]^{-}$were listed for every individual $\mathrm{C}_{n} \mathrm{Cl}_{m}$. All isobaric interferences of $\mathrm{C}_{13} \mathrm{Cl}_{8}$ are shown in Table 3 as an example. $m / z 423$ is the nominal mass of the most abundant isotopic signal of $\left[\mathrm{C}_{13} \mathrm{Cl}_{8}-\mathrm{Cl}\right]^{-}$ $\left(\left[\mathrm{C}_{13} \mathrm{H}_{20}{ }^{35} \mathrm{Cl}_{6}{ }^{37} \mathrm{Cl}\right]^{-}\right)$and is commonly used for quantification of $\mathrm{C}_{13} \mathrm{Cl}_{8}$. The mass clusters of $\left[\mathrm{C}_{10} \mathrm{Cl}_{9}-\mathrm{Cl}\right]^{-},\left[\mathrm{C}_{13} \mathrm{Cl}_{8}-\mathrm{Cl}\right]^{-}$, 
Table 2. Confirmed Ion Formulas in ECNI Mass Spectra ${ }^{a}$

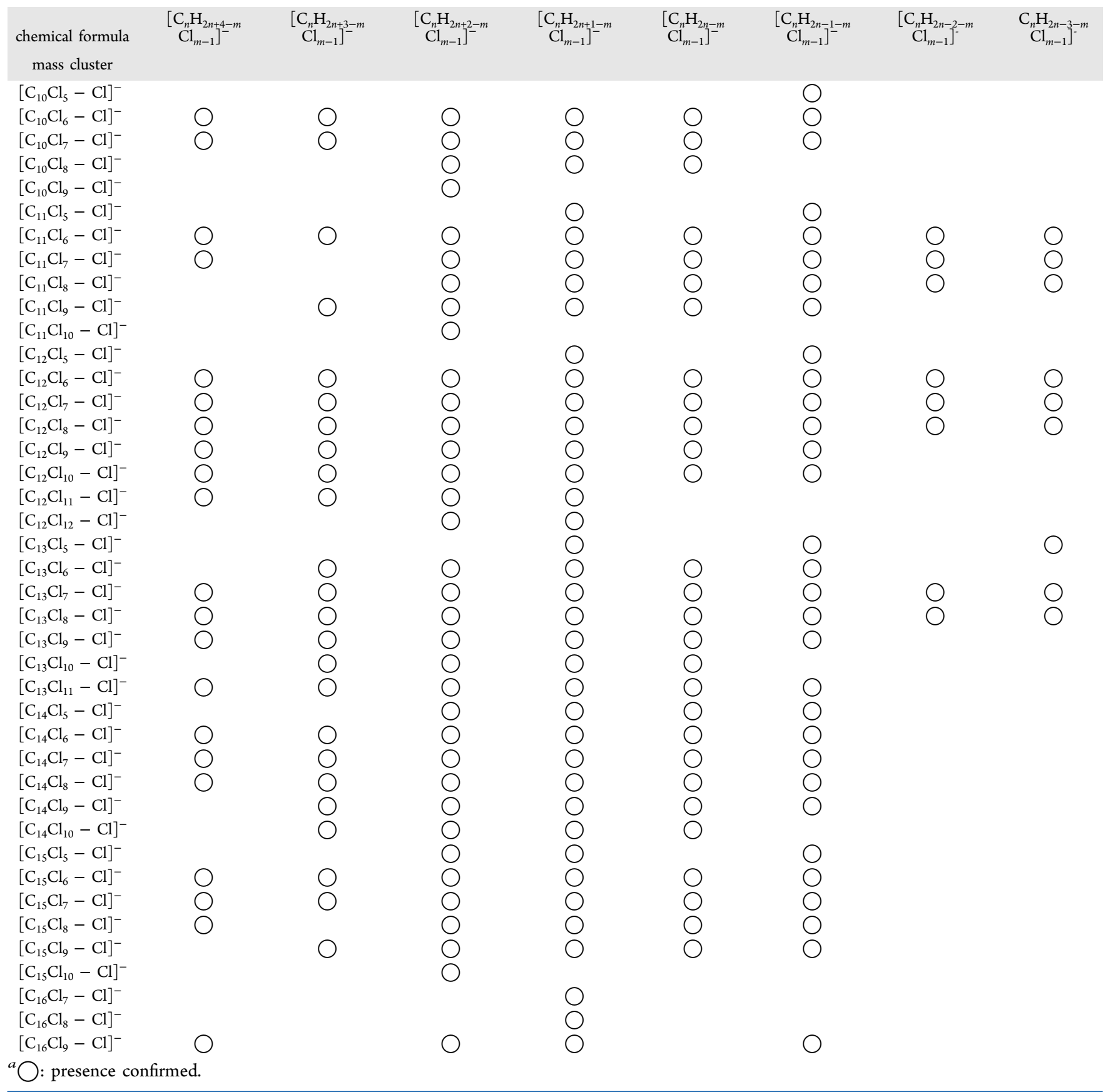

and $\left[\mathrm{C}_{15} \mathrm{Cl}_{7}-\mathrm{Cl}\right]^{-}$all interfere with $\mathrm{m} / z$ 423. To completely avoid interferences from these other species, a resolving power of 94000 would be required. In addition, the isotopic distribution of $\mathrm{C}_{13} \mathrm{Cl}_{8}$ partly overlaps with signals from $\mathrm{C}_{11} \mathrm{Cl}_{9}$ and $\mathrm{C}_{16} \mathrm{Cl}_{7}$ within $\mathrm{m} / z$ 424-429 and $\mathrm{m} / z$ 428-429, respectively.

Using QTOF-MS with a typical resolving power of 10000 , eight species may interfere with the detection of $\left[\mathrm{C}_{13} \mathrm{Cl}_{8}-\right.$ $\mathrm{Cl}]^{-}$. The contribution of $\mathrm{C}_{15} \mathrm{Cl}_{7}$ to individual $\mathrm{m} / z$ values is below $0.42 \%$ of its total abundance, which is negligible in the deconvolution. To deconvolve the remaining seven overlapping formulas from $\left[\mathrm{C}_{13} \mathrm{Cl}_{8}-\mathrm{Cl}\right]^{-}$, eight $\mathrm{m} / z$ are selected. The deconvolution matrix is shown at the bottom of Table 3 . If a low resolution MS was used, a total of 23 overlapping formulas would have to be deconvolved. However, using HRMS with a resolving power of 10000 or higher, the overlapping formulas are generally within the mass cluster of each $[\mathrm{M}-\mathrm{Cl}]^{-}$ $\left(\left[\mathrm{C}_{13} \mathrm{Cl}_{8}-\mathrm{Cl}\right]^{-}\right.$in Table 3$)$.

The isobaric interferences were investigated using the fragment ions observed in the mass spectra of our reference standards. Some other fragment ions could potentially be present in the CPs of a higher chlorination degree, which would alter the isobaric interference list. Therefore, the deconvolution matrices we obtained might only be applicable to process mass spectra of CPs within the chlorination degree range of our reference standards, that is, SCCPs within chlorination degree of $51.5 \% \mathrm{Cl}-63.0 \% \mathrm{Cl}, \mathrm{MCCPs}$ within chlorination degree $42.0 \% \mathrm{Cl}-57.0 \% \mathrm{Cl}$, and LCCPs of chlorination degree around $49 \% \mathrm{Cl}$. 


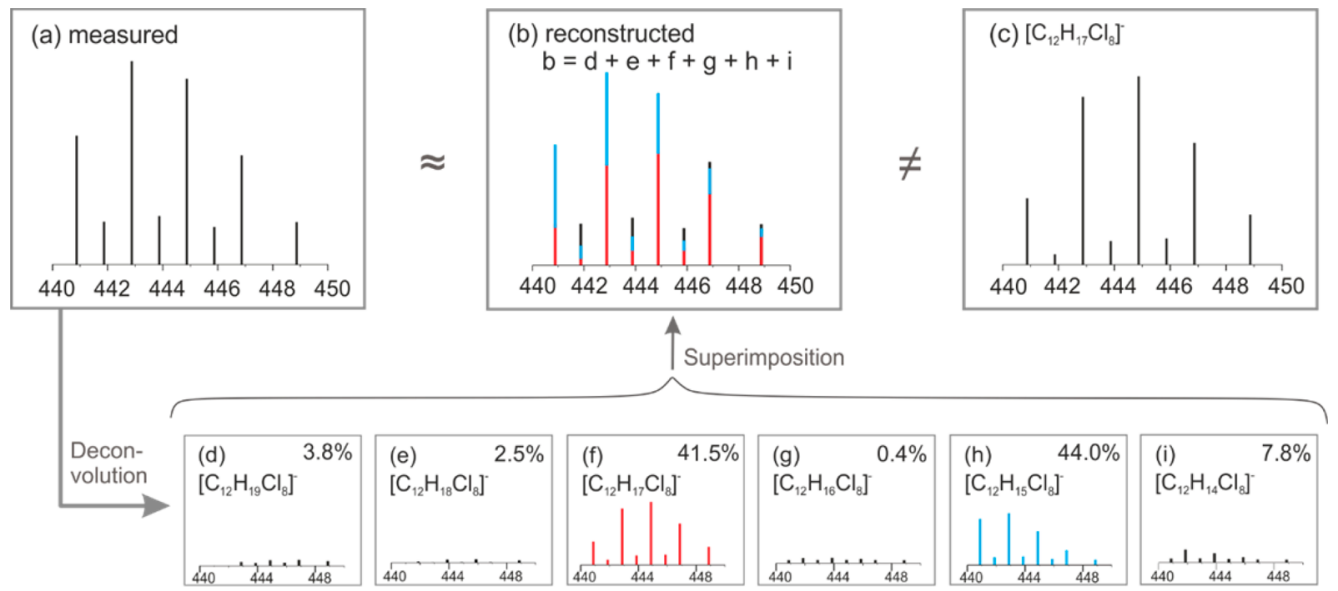

Figure 4. Measured isotope patterns of the $\left[\mathrm{C}_{12} \mathrm{Cl}_{9}-\mathrm{Cl}\right]^{-}$mass cluster (a) and the result of reconstruction of the deconvolved isotope patterns $(\mathrm{b})$ along with the theoretical pattern of $\left[\mathrm{C}_{12} \mathrm{Cl}_{9}-\mathrm{Cl}\right]^{-}$mass cluster $(\mathrm{c})$ in ECNI-QTOF of $\mathrm{C}_{12} 69.98 \% \mathrm{Cl}$. Panels (d) to (i) show the six CP formulas that compose the $\left[\mathrm{C}_{12} \mathrm{Cl}_{9}-\mathrm{Cl}\right]^{-}$mass cluster.

Table 3. Isobaric Interferences of $\left[\mathrm{C}_{13} \mathrm{Cl}_{8}-\mathrm{Cl}\right]^{-}\left(\left[\mathrm{C}_{13} \mathrm{H}_{20} \mathrm{Cl}_{7}\right]^{-}\right)$in ECNI-MS

\begin{tabular}{|c|c|c|c|c|c|c|c|c|c|c|c|c|}
\hline \multirow[b]{2}{*}{ mass cluster } & \multirow[b]{2}{*}{ chemical formula } & \multirow[b]{2}{*}{$\Delta m / z^{a}$} & \multirow[b]{2}{*}{ resolving power } & \multicolumn{9}{|c|}{$\%$ isotopic abundance at $\mathrm{m} / \mathrm{z}$} \\
\hline & & & & 421 & 422 & 423 & 424 & 425 & 426 & 427 & 428 & 429 \\
\hline \multirow[t]{3}{*}[\mathrm{C}_{10}\mathrm{Cl}_{9}-\mathrm{Cl}]{$^{-}$} & {$\left[\mathrm{C}_{10} \mathrm{H}_{12} \mathrm{Cl}_{8}\right]^{-}$} & -0.1022 & 4100 & 1.86 & 0.20 & 0.30 & 0.03 & 0.03 & - & - & - & - \\
\hline & {$\left[\mathrm{C}_{10} \mathrm{H}_{13} \mathrm{Cl}_{8}\right]^{-}$} & -0.0978 & 4300 & 0.78 & 1.86 & 0.20 & 0.30 & 0.03 & 0.03 & 0.00 & - & - \\
\hline & {$\left[\mathrm{C}_{10} \mathrm{H}_{14} \mathrm{Cl}_{8}\right]^{-}$} & -0.0836 & 5100 & 7.23 & 0.78 & 1.86 & 0.20 & 0.30 & 0.03 & 0.03 & - & - \\
\hline \multirow[t]{5}{*}[\mathrm{C}_{11}\mathrm{Cl}_{9}-\mathrm{Cl}]{$^{-}$} & {$\left[\mathrm{C}_{11} \mathrm{H}_{12} \mathrm{Cl}_{8}\right]^{-}$} & - & - & - & - & - & 9.63 & 1.16 & 24.72 & 2.98 & 27.75 & 3.33 \\
\hline & {$\left[\mathrm{C}_{11} \mathrm{H}_{13} \mathrm{Cl}_{8}\right]^{-}$} & - & - & - & - & - & - & 9.63 & 1.17 & 24.71 & 2.98 & 27.75 \\
\hline & {$\left[\mathrm{C}_{11} \mathrm{H}_{14} \mathrm{Cl}_{8}\right]^{-}$} & - & - & - & - & - & - & - & 9.63 & 1.17 & 24.71 & 2.98 \\
\hline & {$\left[\mathrm{C}_{11} \mathrm{H}_{15} \mathrm{Cl}_{8}\right]^{-}$} & - & - & - & - & - & - & - & - & 9.63 & 1.17 & 24.70 \\
\hline & {$\left[\mathrm{C}_{11} \mathrm{H}_{16} \mathrm{Cl}_{8}\right]^{-}$} & - & - & - & - & - & - & - & - & - & 9.63 & 1.17 \\
\hline \multirow[t]{8}{*}[\mathrm{C}_{13}\mathrm{Cl}_{8}-\mathrm{Cl}]{$^{-b}$} & {$\left[\mathrm{C}_{13} \mathrm{H}_{15} \mathrm{Cl}_{7}\right]^{-}$} & -0.0417 & 10000 & 3.82 & 14.49 & 2.03 & 4.69 & 0.65 & 0.92 & 0.12 & 0.10 & 0.01 \\
\hline & {$\left[\mathrm{C}_{13} \mathrm{H}_{16} \mathrm{Cl}_{7}\right]^{-}$} & -0.0372 & 11000 & 26.98 & 3.82 & 14.49 & 2.04 & 4.69 & 0.65 & 0.92 & 0.12 & 0.10 \\
\hline & {$\left[\mathrm{C}_{13} \mathrm{H}_{17} \mathrm{Cl}_{7}\right]^{-}$} & -0.0231 & 18000 & 3.99 & 26.97 & 3.82 & 14.49 & 2.04 & 4.69 & 0.65 & 0.92 & 0.13 \\
\hline & {$\left[\mathrm{C}_{13} \mathrm{H}_{18} \mathrm{Cl}_{7}\right]^{-}$} & -0.0186 & 23000 & 27.95 & 3.99 & 26.97 & 3.83 & 14.49 & 2.04 & 4.69 & 0.65 & 0.92 \\
\hline & {$\left[\mathrm{C}_{13} \mathrm{H}_{19} \mathrm{Cl}_{7}\right]^{-}$} & -0.0045 & 94000 & 1.78 & 27.95 & 3.99 & 26.97 & 3.83 & 14.49 & 2.04 & 4.69 & 0.65 \\
\hline & {$\left[\mathrm{C}_{13} \mathrm{H}_{20} \mathrm{Cl}_{7}\right]^{-}$} & 0.0000 & - & 12.43 & 1.79 & $27.95^{b}$ & 4.00 & 26.96 & 3.83 & 14.49 & 2.04 & 4.69 \\
\hline & {$\left[\mathrm{C}_{13} \mathrm{H}_{21} \mathrm{Cl}_{7}\right]^{-}$} & +0.0141 & 30000 & - & 12.43 & 1.79 & 27.95 & 4.00 & 26.96 & 3.83 & 14.49 & 2.04 \\
\hline & {$\left[\mathrm{C}_{13} \mathrm{H}_{22} \mathrm{Cl}_{7}\right]^{-}$} & +0.0186 & 24000 & - & - & 12.43 & 1.79 & 27.94 & 4.00 & 26.96 & 3.84 & 14.48 \\
\hline \multirow[t]{6}{*}[\mathrm{C}_{15}\mathrm{Cl}_{7}-\mathrm{Cl}]{$^{-}$} & {$\left[\mathrm{C}_{15} \mathrm{H}_{22} \mathrm{Cl}_{6}\right]^{-}$} & +0.0384 & 11000 & 0.42 & 0.35 & 0.05 & 0.02 & - & - & - & - & - \\
\hline & {$\left[\mathrm{C}_{15} \mathrm{H}_{23} \mathrm{Cl}_{6}\right]^{-}$} & +0.0535 & 8100 & 2.65 & 0.42 & 0.35 & 0.05 & 0.02 & - & - & - & - \\
\hline & {$\left[\mathrm{C}_{15} \mathrm{H}_{24} \mathrm{Cl}_{6}\right]^{-}$} & +0.0570 & 7500 & 1.74 & 2.65 & 0.42 & 0.35 & 0.05 & 0.02 & - & - & - \\
\hline & {$\left[\mathrm{C}_{15} \mathrm{H}_{25} \mathrm{Cl}_{6}\right]^{-}$} & +0.0711 & 6000 & 10.81 & 1.74 & 2.65 & 0.42 & 0.35 & 0.05 & 0.02 & - & - \\
\hline & {$\left[\mathrm{C}_{15} \mathrm{H}_{26} \mathrm{Cl}_{6}\right]^{-}$} & +0.0756 & 5600 & 4.09 & 10.81 & 1.75 & 2.65 & 0.42 & 0.35 & 0.05 & 0.02 & - \\
\hline & {$\left[\mathrm{C}_{15} \mathrm{H}_{27} \mathrm{Cl}_{6}\right]^{-}$} & +0.0801 & 5300 & 25.00 & 4.09 & 10.81 & 1.75 & 2.65 & 0.42 & 0.35 & 0.05 & 0.02 \\
\hline$\left[\mathrm{C}_{16} \mathrm{Cl}_{7}-\mathrm{Cl}\right]^{-}$ & {$\left[\mathrm{C}_{16} \mathrm{H}_{26} \mathrm{Cl}_{6}\right]^{-}$} & - & - & - & - & - & - & - & - & - & 15.87 & 2.81 \\
\hline
\end{tabular}

${ }^{a} \Delta m / z$ is the $m / z$ difference between the confirmation ion $\left[\mathrm{C}_{13} \mathrm{Cl}_{8}-\mathrm{Cl}\right]^{-}\left({ }^{b} \mathrm{C}_{13} \mathrm{H}_{20}{ }^{35} \mathrm{Cl}_{6}^{37} \mathrm{Cl}, 422.9355 \mathrm{amu}\right)$ and the isobaric interferences. ${ }^{b} \mathrm{The}$ deconvolution matrix for an instrument with 10000 resolving power is:

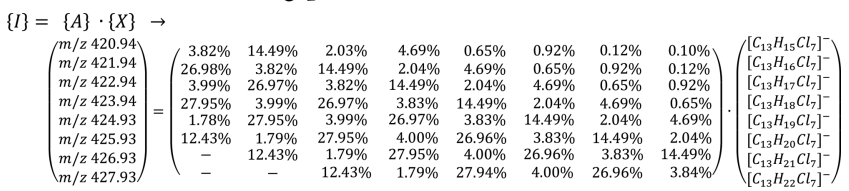

When implementing the method to a certain instrument, one can begin with applying the results in Table 3 to check the isotopic distribution and centroid mass shifts in full-scan mode. If the reconstructed isotopic distribution and/or centroid mass shifts are not closer to expected values for the standards after deconvolution, the procedure should be done again on the instrument to check if there are other overlapped ions not enumerated in Table 3. The number of overlapped ions may vary due to performance of individual instrument. The ions which do not overlap the confirmation ions can be removed from the deconvolution candidate list in order to reduce the number of ions that are selected for subsequent analysis in SIM mode. Some overlapped ions may be resolved by the instrument when operating in SIM mode and can also be removed from the deconvolution candidate list. 
Data-Processing Approach in APCl. The complete processing approach for APCI mass spectra is described in the Supporting Information analogously to the description for ECNI above. In addition to the observed chloride adducts (confirmation ion), the mass spectra showed fragmentation of $\mathrm{CPs}$ consisting solely of successive losses of $\mathrm{HCl}$, which made the deconvolution of isobaric interferences in APCI less complicated than in ECNI. Using an instrument with a resolving power of $10000,\left[\mathrm{C}_{n} \mathrm{Cl}_{m+1}+\mathrm{Cl}-\mathrm{HCl}\right]^{-}$is the only interference with the confirmation ion $\left[\mathrm{C}_{n} \mathrm{Cl}_{m}+\mathrm{Cl}\right]^{-}$in most cases.

Applications. $C_{n} C l_{m}$ Signal Calibration. Relative amounts of $\mathrm{C}_{n} \mathrm{Cl}_{m}$ were determined by the signals of their confirmation ions, i.e. $\left[\mathrm{C}_{n} \mathrm{Cl}_{m}-\mathrm{Cl}\right]^{-}$for ECNI-MS and $\left[\mathrm{C}_{n} \mathrm{Cl}_{m}+\mathrm{Cl}\right]^{-}$for APCI-MS. These signals are significantly interfered with other fragment ions using an instrument of insufficient resolving power. The data-processing approach was applied to deconvolve unresolved signals. The improvement in signal calibration due to the deconvolution approach can be quantified, as shown for the $\mathrm{C}_{12} 69.98 \% \mathrm{Cl}$ chain length standards in Figure 5. In ECNI-QTOF, unresolved ions lead to
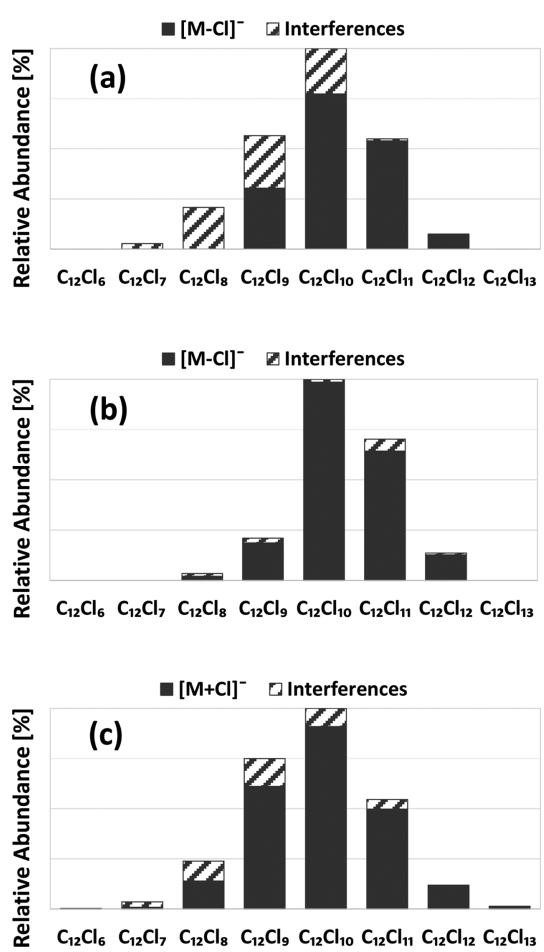

Figure 5. Superimposition of the deconvolved $\mathrm{C}_{n} \mathrm{Cl}_{m}$ patterns in $\mathrm{C}_{12}$ $69.98 \% \mathrm{Cl}$ chain length standards (gray bars) and the interferences (dashed bars) using (a) GC/ECNI-QTOF, (b) GC/ECNI-magnetic sector HRMS, and (c) APCI-QTOF.

false positive results $\left(\mathrm{C}_{12} \mathrm{Cl}_{7}\right.$ and $\mathrm{C}_{12} \mathrm{Cl}_{8}$ in Figure 5a). With a magnetic sector HRMS in SIM mode, unresolved ions lead to an overestimation up to $70 \%\left(\mathrm{C}_{12} \mathrm{Cl}_{8}\right.$ in Figure $\left.5 \mathrm{~b}\right)$. In APCIQTOF, the error of $\left[\mathrm{C}_{n} \mathrm{Cl}_{m}+\mathrm{Cl}\right]^{-}$is up to $372 \%\left(\mathrm{C}_{12} \mathrm{Cl}_{6}\right.$ in Figure 5c).

Resolving Congener Groups in Environmental Samples. The signal calibration of $\mathrm{C}_{n} \mathrm{Cl}_{m}$ should also be applicable to the analysis of CPs in environmental samples where signal interference from the matrix is possible. In a conventional SCCP analysis, the relative amounts of congener groups are identified using only one $\mathrm{m} / z$ signal intensity per group. ${ }^{17}$
Using the deconvolution algorithm (i.e., eq 1), the congener groups are identified by monitoring several $\mathrm{m} / \mathrm{z}$ per group. In principle, our method that considers more $\mathrm{m} / z$ could be either more or less sensitive to signal interference. To test the sensitivity of our method, we spiked two fish samples and one sediment sample with known amounts of SCCP $63.0 \% \mathrm{Cl}$ mixture standard and analyzed them by GC/ECNI-magnetic sector HRMS (for sample cleanup, see the Supporting Information). The samples were spiked at environmentally realistic concentrations (approximately $1000 \mathrm{ng} / \mathrm{g}$ lipid weight in fish samples and $40 \mathrm{ng} / \mathrm{g}$ dry weight in sediment sample). The expected amounts of 12 major congener groups $\left(\mathrm{C}_{n} \mathrm{Cl}_{7}-\right.$ $\left.\mathrm{C}_{n} \mathrm{Cl}_{9}, 10 \leqslant n \leqslant 13\right)$ spiked in the 3 samples were compared with the amounts measured by using only one $m / z$ and the amounts deconvolved by several $\mathrm{m} / z$, respectively. The range of measured amounts $(n=36)$ was between $32 \%$ lower and $165 \%$ higher than the spiked amount using conventional analysis, and between $44 \%$ lower and $54 \%$ higher than the spiked amount using deconvolution. Therefore, in this exemplary test, the deconvolution method was not more sensitive to signal interference in environmental samples compared to conventional methods.

$\mathrm{C}_{n} \mathrm{Cl}_{m}$ Identification. Congeners with carbon chains shorter than 10 carbons may also exist in technical CP mixtures or environmental samples, although they have not been produced intentionally. ${ }^{24}$ No particular reference standards are available for shorter chain CP analysis, but they can still be identified by data processing of $\mathrm{CP}$ mass spectra. For example, the GC retention time of $\mathrm{CPs}$ in some lubricant extracts was shorter than that of SCCP reference standards, indicating shorter carbon chain CPs such as $\mathrm{C}_{9}$ homologues. These samples were analyzed by magnetic sector HRMS. For each $\mathrm{C}_{9}$ homologue congener group $\left(\mathrm{C}_{9} \mathrm{Cl}_{5}\right.$ to $\left.\mathrm{C}_{9} \mathrm{Cl}_{9}\right)$, all possible ions were enumerated according to the general fragmentation pathways. The relative amount of each $\mathrm{C}_{9} \mathrm{Cl}_{m}$ was thereafter deconvolved. The data-processing flowsheet of $\mathrm{C}_{9}$ identification is shown in the Supporting Information (Figure S-5).

Instrumental Parameter Optimization. The data-processing approach deconvolves relative amounts of fragment ions, which can be a criterion for optimizing instrumental parameters. Optimization of the collision energy in APCIQTOF is illustrated as an example. The relationship between the applied collision energy and relative amounts of fragment ions is shown in Figure 6. $\left[\mathrm{C}_{13} \mathrm{Cl}_{11}+\mathrm{Cl}-3 \mathrm{HCl}\right]^{-}$and $\left[\mathrm{C}_{13} \mathrm{Cl}_{12}+\mathrm{Cl}-4 \mathrm{HCl}\right]^{-}$were present when the collision energy exceeded $7 \mathrm{~V}$. $\left[\mathrm{C}_{13} \mathrm{Cl}_{9}+\mathrm{Cl}-\mathrm{HCl}\right]^{-}$was the only interference ion in the case of a collision energy below $2 \mathrm{~V}$. The relative amount of $\left[\mathrm{C}_{13} \mathrm{Cl}_{8}+\mathrm{Cl}\right]^{-}$was highest at a collision

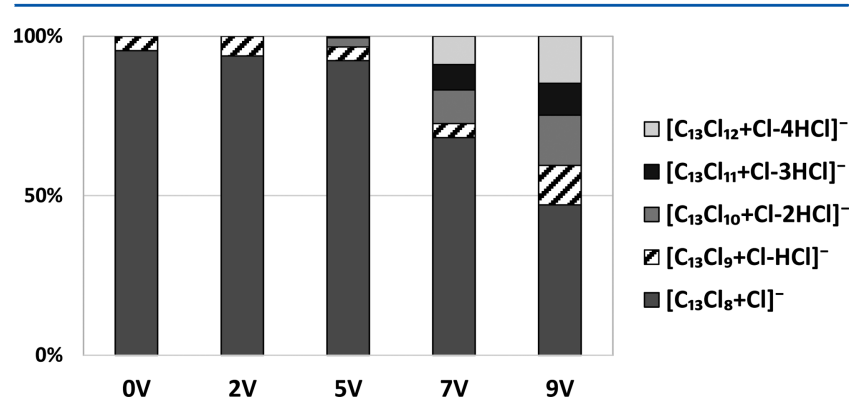

Figure 6. Fragment ion composition of the $\left[\mathrm{C}_{13} \mathrm{Cl}_{8}+\mathrm{Cl}\right]^{-}$mass cluster in SCCP $63.0 \% \mathrm{Cl}$ mixture standard at different collision energies using APCI-QTOF. 
energy of $0 \mathrm{~V}$. An increasing number of fragment ion species will upsize the deconvolution matrix, which can become unsolvable (an unsolvable example is shown in Table S-7). A collision energy below $2 \mathrm{~V}$ would thus be chosen in this example.

\section{CONCLUSIONS}

We present an innovative approach that allows CP congener groups to be resolved from complex full-scan mass spectra by applying fragmentation rules extrapolated from a limited set of reference standards. The approach has been demonstrated using two ionization techniques for CP analysis (i.e., ECNI-MS and APCI-MS) and can be fit to the data from additional ionization techniques. To implement our method in the quantitative analysis of individual congener groups in complex samples, response factors for each congener group are required, which are not available at present and require further investigations. However, correct deconvolution of all interfering chemical formulas is a prerequisite for accurate CP quantification. Recognizing the enormous production volumes of CPs worldwide and the growing concern about their potential environmental impacts, reliable monitoring data for CPs are urgently needed. Our approach is a large step toward filling this need.

\section{ASSOCIATED CONTENT}

\section{S Supporting Information}

The Supporting Information is available free of charge on the ACS Publications website at DOI: 10.1021/acs.analchem.6b01172.

Additional information as noted in text (PDF)

\section{AUTHOR INFORMATION}

\section{Corresponding Author}

*E-mail: bo.yuan@aces.su.se.

\section{Notes}

The authors declare no competing financial interest.

\section{ACKNOWLEDGMENTS}

The lubricant samples were kindly provided by the Department of Materials and Environmental Chemistry, Stockholm University. Ulla Eriksson and Lukas Mustajärvi at ACES are acknowledged for providing sample extracts. Furthermore, the authors would like to thank Michael Strandell, Ulrika E. Fridén, and Ulla Wideqvist at ACES for sharing their valuable knowledge and experience of mass spectrometry and chlorinated paraffins. Pascal S. Diefenbacher at ETH Zürich is acknowledged for his support to the magnetic sector HRMS measurements. The Swiss National Science Foundation (SNF) is acknowledged for providing a travel grant to Bo Yuan to ETH Zürich (grant no. IZK0Z2-163272).

\section{REFERENCES}

(1) Muir, D. C. G.; Stern, G. A.; Tomy, G. T. Chapter 8: chlorinated paraffins; Springer-Verlag: Berlin, 2000; Vol. 3.

(2) Glüge, J.; Wang, Z.; Bogdal, C.; Scheringer, M.; Hungerbühler, K. Sci. Total Environ 2016, 32, in press DOI: 10.1016/j.scitotenv.2016.1008.1105.

(3) UNEP. POPRC-11/3: Short-chained chlorinated paraffins; United Nations Environmental Programme: Stockholm, Sweden, 2015.

(4) van Mourik, L. M.; Leonards, P. E.; Gaus, C.; de Boer, J. Chemosphere 2015, 136, 259-272.
(5) Xia, D.; Gao, L. R.; Zhu, S.; Zheng, M. H. Anal. Bioanal. Chem. 2014, 406, 7561-7570.

(6) Pellizzato, F.; Ricci, M.; Held, A.; Emons, H. J. Environ. Monit. 2007, 9, 924-930.

(7) Bogdal, C.; Alsberg, T.; Diefenbacher, P. S.; MacLeod, M.; Berger, U. Anal. Chem. 2015, 87, 2852-2860.

(8) Castillo Tirado, A.; Gracia Lor, E.; Roig Navarro, A. F.; Sancho Llopis, J. V.; Rodriguez-González, P.; García Alonso, J. I. Anal. Chim. Acta 2013, 765, 77-85.

(9) Olson, M. T.; Yergey, A. L. J. Am. Soc. Mass Spectrom. 2009, 20, 295-302.

(10) Zhang, Z. Q.; Guan, S. H.; Marshall, A. G. J. Am. Soc. Mass Spectrom. 1997, 8, 659-670.

(11) Peppernick, S. J.; Gunaratne, K. D. D.; Castleman, A. W. Int. J. Mass Spectrom. 2010, 290, 65-71.

(12) Dobo, A.; Kaltashov, I. A. Anal. Chem. 2001, 73, 4763-4773.

(13) Marchetti, A. A.; Mignerey, A. C. Nucl. Instrum. Methods Phys. Res., Sect. A 1993, 324, 288-296.

(14) Hilmer, R. M.; Taylor, J. W. Anal. Chem. 1974, 46, 1038-1044.

(15) Meija, J.; Caruso, J. A. J. Am. Soc. Mass Spectrom. 2004, 15, 654658.

(16) Roussis, S. G.; Proulx, R. Anal. Chem. 2003, 75, 1470-1482.

(17) Tomy, G. T.; Stern, G. A.; Muir, D. C. G.; Fisk, A. T.; Cymbalisty, C. D.; Westmore, J. B. Anal. Chem. 1997, 69, 2762-2771.

(18) Tomy, G. T.; Tittlemier, S. A.; Stern, G. A.; Muir, D. C. G.; Westmore, J. B. Chemosphere 1998, 37, 1395-1410.

(19) Zencak, Z.; Reth, M.; Oehme, M. Anal. Chem. 2003, 75, 24872492.

(20) Stemmler, E. A.; Hites, R. A. Anal. Chem. 1985, 57, 684-692.

(21) Zencak, Z.; Oehme, M. Rapid Commun. Mass Spectrom. 2004, $18,2235-2240$.

(22) Gjos, N.; Gustavsen, K. O. Anal. Chem. 1982, 54, 1316-1318.

(23) Gallistl, C.; Vetter, W. Organohalogen Compd. 2015, 77, 427431.

(24) Reth, M.; Oehme, M. Anal. Bioanal. Chem. 2004, 378, 17411747. 